\title{
Postoperative Complications and Curative Effect of Interventional Diagnosis and Treatment through Radial Artery and Femoral Artery
}

\author{
LI LE SHI, W. X. PENG, MING ZHAO ${ }^{1}$, X. Z. HE AND J. Y. CHEN²*
}

Department of Vascular Cardiology, Zhuhai People's Hospital (Zhuhai Hospital Affiliated with Jinan University), Zhuhai, Guangdong 519000, 'The First Affiliated Hospital, Sun Yat-sen University, Guangzhou, Guangdong 510080, ${ }^{2}$ Department of Vascular Cardiology, Guangdong Provincial People's Hospital, Guangdong 510080, China

Shi et al.: Interventional Diagnosis and Treatment through Radial Artery and Femoral Artery

\begin{abstract}
To investigate the efficacy and safety of percutaneous coronary intervention in patients with coronary heart disease via radial and femoral artery pathways. Total 122 patients with coronary heart disease who underwent percutaneous coronary intervention in our hospital were selected and divided into observation group ( $n=61$, percutaneous coronary intervention via radial artery) and control group ( $n=61$, percutaneous coronary intervention via femoral artery). The perioperative conditions (operation time, puncture time, postoperative bed rest time and hospital stay) of the two groups were compared. Before and 3 mo after the operation, the heart function indexes [left ventricular ejection fraction, left ventricular end systolic diameter] operation success rate and related complications. There was no significant difference in the stenosis degree of left anterior descending, left circumflex artery, right coronary artery, calcification, angulation and target vessel between the two groups $(p>0.05)$. The puncture time, operation time, postoperative bed time and hospitalization time of the observation group were lower than those of the control group $(\mathbf{p}<0.05)$. There was no significant difference in the success rate of percutaneous coronary intervention between the observation group and the control group ( $\mathbf{p}>\mathbf{0 . 0 5})$. In addition, 3 mo after operation, left ventricular ejection fraction and left ventricular end systolic diameter in both groups were lower than those before operation (all $\mathbf{p}<0.05)$. Finally, the incidence of puncture site complications in the observation group was lower than that in the control group $(p<0.05)$. The effect of transradial and femoral percutaneous coronary intervention in the treatment of coronary heart disease is similar, but the recovery is faster, the incidence of postoperative complications and serious cardiovascular adverse events is lower, and the safety is higher.
\end{abstract}

Key words: Coronary heart disease, percutaneous coronary intervention, radial artery pathway, femoral artery pathway

Coronary Heart Disease (CHD) is a common cardiovascular disease ${ }^{[1,2]}$, mainly due to coronary atherosclerosis caused by cardiovascular obstruction, leading to myocardial ischemia and onset, more common in the elderly patients ${ }^{[3,4]}$. The common symptoms are paroxysmal angina pectoris or tenderness in the precordial area, which seriously affect physical and mental health and quality of life of patients ${ }^{[4]}$. At present, Percutaneous Coronary Intervention (PCI) is the main method for the treatment of $\mathrm{CHD}^{[5-7]}$, which uses catheter technology to relieve coronary artery stenosis and occlusion, promote the recovery of myocardial blood supply and has good therapeutic effect ${ }^{[8]}$. There are two approaches to PCI, namely transradial or femoral approaches. Relevant studies have shown that different approaches to PCI have different therapeutic effects $^{[9]}$. In this study, 122 patients with CHD in our hospital were selected and divided into two groups to study the efficacy and safety of PCI via radial artery and femoral artery.

*Address for correspondence

E-mail: chen-jiyan@163.com 
A total of 122 patients with CHD diagnosed by PCI in our hospital from January 2019 to January 2021 were selected and divided into two groups according to different operation paths. The control group $(\mathrm{n}=61)$ and the observation group $(n=61)$. There were 20 females and 41 males in the control group; age ranged from 49 to 78 y old, with an average age of (64.29 \pm 7.64$) y$ old, the course of disease was 3-9 y, the average course of disease was $(5.87 \pm 1.64)$ y. Complications with 35 cases of hypertension, 19 cases of hyperglycemia and 20 cases of hyperlipidemia. The observation group included 61 cases, 18 females and 43 males; age ranged from 50 to $80 \mathrm{y}$ old, with an average of (65.37 \pm 7.81$)$ y old. The course of disease was 2-9 y. The average course of disease was $(5.59 \pm 1.48) \mathrm{y}$. Complications with 37 cases of hypertension, 20 cases of hyperglycemia and 18 cases of hyperlipidemia. There was no significant difference in baseline data between the two groups $(p>0.05)$. Inclusion criteria includes the diagnostic criteria of coronary heart disease refer to the criteria in coronary angiography and clinical ${ }^{[7]}$; the diagnosis was confirmed by electrocardiography or coronary angiography; PCI was performed; informed of the study and signed the consent. Exclusion criteria includes patients with congenital heart disease; Coagulation dysfunction; patients with rheumatic heart disease; severe hepatic and renal insufficiency; patients with malignant tumor; patients with severe immune deficiency; those who are not willing to cooperate with the completion of the study. For patients scheduled for elective surgery, aspirin $100 \mathrm{mg} / \mathrm{d}$ and clopidogrel $75 \mathrm{mg} / \mathrm{d}$ were taken orally $3 \mathrm{~d}$ before operation. For patients undergoing emergency operation, aspirin 300 $\mathrm{mg}$ and clopidogrel $300-500 \mathrm{mg}$ were taken orally within $24 \mathrm{~h}$ before operation. PCI was performed via femoral artery. The patient was supine and the puncture point was selected at $2 \mathrm{~cm}$ below the femoral transverse striae. Lidocaine $(2 \%)$ was used for local anesthesia. $20 \mathrm{G}$ puncture needles were used for puncture and the angle of puncture was $40^{\circ}$ degrees to the skin. During the puncture process, the action should be slow. When the blood vessel is punctured, the pulsatile blood flow can be seen gushing out through the hollow probe. Then, the guide wire is inserted and the $7 \mathrm{~F}$ artery sheath is put into the puncture. According to the results of arteriography, appropriate stents and balloons were selected. 3000-4000 $\mu$ heparin was given regularly during the operation. The arterial sheath was removed 4 $h$ after the operation, and the tourniquet was used to stop bleeding. After complete hemostasis, pressure bandage was applied. Allen test was positive before PCI, which indicated that the pulsation of radial artery was good. 129
The patient was lying on his back, holding up his left upper limb and abducting for $25 \mathrm{~min}$. The puncture point was selected at $1 \mathrm{~cm}$ near the styloid process of radius. The anesthesia method and follow-up operation were the same as those in the control group. After operation, both groups were given a $24 \mathrm{~h}$ rest, aspirin $100 \mathrm{mg} / \mathrm{d}$ and clopidogrel $75 \mathrm{mg} / \mathrm{d}$. The target lesion vessels were completely covered by stents without sufficient dilatation, residual stenosis $<20 \%$, Thrombolysis in Myocardial Infarction (TIMI) blood flow grade $\geq 3$. In addition, no death, acute myocardial infarction, acute vascular occlusion and other serious complications occurred within $30 \mathrm{~d}$ after operation. The success rate of PCI in two groups; perioperative conditions (operation time, puncture time, hospital stay, X-ray exposure time, postoperative bed rest time); Left Ventricular Ejection Fraction (LVEF) and Left Ventricular End Systolic Diameter (LVESD) were measured before and 3 mo after operation; postoperative complications of the two groups, including urinary retention, subcutaneous congestion, vagal reflex, puncture site hematoma and pseudoaneurysm. Statistical software Statistical Package For The Social Sciences (SPSS) 22.0 was used to analyze the data of this study. Using $(\mathrm{x} \pm \mathrm{s}) \mathrm{T}$ test was used for inter group analysis; the counting data were analyzed by X-test. $\mathrm{p}<0.05$ was considered statistically significant. The success rate of PCI was $95.08 \%(58 / 61)$ in the observation group and $98.36 \%$ $(60 / 61)$ in the control group. The results showed that there was no significant difference in the success rate of PCI between the two groups ( $p>0.05$ ), as shown in Table 1. There was no significant difference in the stenosis degree of Left Anterior Descending Artery (LAD), Left Circumflex Artery (LCX), Right Coronary Artery (RCA), calcification lesion, angulation lesion and target vessel lesion between the observation group and the control group ( $>00.05)$, as shown in Table 2 . There was no significant difference in operation time between the two groups $(p>0.05)$; the puncture time and hospital stay of the observation group were shorter than those of the control group (all $p<0.001$ ), as shown in Table 3.

In the observation group, 1 case was with hematoma at the puncture site, 1 case with arterial spasm, 1 case with vasovagal reflex and 1 case with urinary retention. In the control group, 5 cases with hematoma at the puncture site, 2 cases with pseudoaneurysm, 2 cases with arteriovenous fistula, 4 cases with vasovagal reflex, 2 cases with urinary retention. The related complication rate of the observation group was 4.92 $\%$ (3/61), which was lower than $18.03 \%(11 / 61)$ 
of the control group ( $<<0.05)$, as shown in Table 4 . Before operation, there was no significant difference in LVEF and LVESD between the two groups (all p>0.05). 3 mo after operation, LVEF and LVESD of the two groups were lower than those before operation (all $\mathrm{p}<0.05$ ), as shown in Table 5. The classic method of PCI for CHD is via femoral artery. The puncture operation is simple and the success rate of PCI is high. However, the incidence of local complications such as subcutaneous hematoma, congestion, vagus reflex and pseudoaneurysm after femoral artery approach is high, which is not conducive to the postoperative rehabilitation of patients ${ }^{[10,11]}$. At present, the majority of CHD patients are the elderly. The immune function of the elderly patients is reduced, the blood circulation is poor, and the postoperative recovery is slower ${ }^{[12-14]}$. In recent years, PCI has been gradually applied via radial artery pathway. It is relatively easy to stop bleeding after PCI, which is conducive to reducing the incidence of postoperative complications. However, the radial artery lumen is small, the puncture difficulty is high, and improper operation can cause radial artery spasm, leading to PCI failure. Therefore, this approach requires clinicians to have rich experience in operation ${ }^{[15,16]}$.

TABLE 1: COMPARISON OF PCL SUCCESS RATE BETWEEN THE TWO GROUPS

\begin{tabular}{lcc}
\hline Group & $\mathbf{n}$ & $\mathrm{PCl}$ success rate \\
\hline Observation group & 61 & $58(95.08 \%)$ \\
Control group & 61 & $60(98.36 \%)$ \\
\hline
\end{tabular}

TABLE 2: COMPARISON OF CORONARY ARTERY LESIONS BETWEEN THE TWO GROUPS

\begin{tabular}{|c|c|c|c|c|c|c|c|}
\hline Group & $\mathrm{n}$ & LAD & LCX & $\mathrm{RCA}$ & $\begin{array}{c}\text { Calcified } \\
\text { lesions }\end{array}$ & $\begin{array}{c}\text { Bifurcation } \\
\text { lesions }\end{array}$ & $\begin{array}{c}\text { Degree of } \\
\text { stenosis }\end{array}$ \\
\hline $\begin{array}{l}\text { Observation } \\
\text { group }\end{array}$ & 61 & $20(32.8)$ & $27(44.3)$ & $23(37.7)$ & $11(18.0)$ & $15(24.6)$ & $81.3 \pm 3.8$ \\
\hline Control group & 61 & $17(27.9)$ & 34 (55.7) & $18(29.5)$ & $8(13.1)$ & $11(18.0)$ & $80.5 \pm 2.6$ \\
\hline $\mathrm{t}$ & & 0.238 & 0.800 & 0.503 & 0.392 & 0.872 & 1.099 \\
\hline $\mathrm{p}$ & & $>0.05$ & $>0.05$ & $>0.05$ & $>0.05$ & $>0.05$ & $>0.05$ \\
\hline
\end{tabular}

TABLE 3: COMPARISON OF PUNCTURE OPERATION BETWEEN THE TWO GROUPS

\begin{tabular}{lcccc}
\hline Group & $\mathrm{n}$ & $\mathrm{PCl}$ time $(\mathrm{min})$ & Puncture time $(\mathrm{min})$ & Hospital stay $(\mathrm{d})$ \\
\hline Control group & 61 & $62.06 \pm 10.98$ & $10.19 \pm 2.58$ & $7.56 \pm 1.40$ \\
Observation group & 61 & $60.22 \pm 11.30$ & $5.26 \pm 1.55$ & $5.11 \pm 1.23$ \\
$\mathrm{t}$ & & 1.011 & 14.185 & 11.386 \\
$\mathrm{p}$ & & 0.314 & $<0.001$ & $<0.001$ \\
\hline
\end{tabular}

TABLE 4: COMPARISON OF SURGICAL COMPLICATIONS BETWEEN TWO GROUPS OF PCI PATIENTS

\begin{tabular}{|c|c|c|c|c|c|c|c|}
\hline Group & $\mathrm{n}$ & $\begin{array}{c}\text { Urinary } \\
\text { retention }\end{array}$ & $\begin{array}{c}\text { Subcutaneous } \\
\text { congestion }\end{array}$ & $\begin{array}{c}\text { Puncture site } \\
\text { hematoma }\end{array}$ & Vagus reflex & Pseudoaneurysm & $\begin{array}{c}\text { Total } \\
\text { incidence }\end{array}$ \\
\hline $\begin{array}{l}\text { Observation } \\
\text { group }\end{array}$ & 61 & $0(0.00)$ & $1(1.64)$ & $1(1.64)$ & $1(1.64)$ & $0(0.00)$ & $3(4.92)$ \\
\hline Control group & 61 & $1(1.64)$ & $3(4.92)$ & $3(4.92)$ & $2(3.28)$ & $2(3.28)$ & $11(18.03)$ \\
\hline $\mathrm{t}$ & & & & & & & 5.674 \\
\hline $\mathrm{p}$ & & & & & & & $<0.05$ \\
\hline
\end{tabular}

TABLE 5: COMPARISON OF CARDIAC FUNCTION INDEXES BETWEEN THE TWO GROUPS

\begin{tabular}{llcccc}
\hline \multirow{2}{*}{ Group } & $\mathrm{n}$ & \multicolumn{2}{c}{ LVEF } & \multicolumn{2}{c}{ LVESD } \\
\cline { 3 - 6 } & & Before $\mathrm{PCl}$ & After $\mathrm{PCl}$ & Before PCl & $\mathrm{After} \mathrm{PCl}$ \\
\hline Observation group & 61 & $35.58 \pm 4.19$ & $56.12 \pm 4.89^{* \#}$ & $5.12 \pm 0.41$ & $3.95 \pm 0.46^{* \#}$ \\
Control group & 61 & $36.12 \pm 4.37$ & $57.28 \pm 5.06^{*}$ & $5.06 \pm 0.47$ & $3.89 \pm 0.52^{*}$ \\
\hline
\end{tabular}

Note: Compared with the same group before operation, ${ }^{*} \mathrm{p}<0.05$. Compared with the control group, ${ }^{\#} \mathrm{p}<0.05$; LVEF: left ventricular ejection fraction; LVESD: left ventricular end systolic diameter 
Femoral artery approach is a common approach for PCI, because the femoral artery is thicker and less deformity, it is conducive to intraoperative operation. However, the femoral artery is adjacent to important nerves and blood vessels and improper treatment or puncture with conventional heparin can cause hematoma, pseudoaneurysm and other complications at the puncture site ${ }^{[17,18]}$. In addition, the need for bed rest after surgery increases the risk of complications, which affects the process of postoperative rehabilitation. The results showed that the puncture time and hospital stay of the observation group were shorter than those of the control group, and the incidence of complications at the puncture site was lower than that of the control group, suggesting that radial artery approach can reduce the incidence of complications and is conducive to the prognosis. Compared with the femoral artery approach, the radial artery approach has a shallower anatomic position and thinner blood vessels. There are no important nerves and blood vessels around the radial artery, which can avoid the injury of nerves and arteriovenous sinuses. Besides, there is a radial styloid process on the lateral side, which is easy to compress and stop bleeding after operation, reducing the amount of bleeding, and contributing to postoperative rehabilitation $^{[19-21]}$. In addition, compared with femoral artery approach, radial artery approach can get out of bed early without strict braking, which is helpful to reduce complications and accelerate the rehabilitation process of patients. From the results of this study, 3 mo after operation, LVEF and LVESD of the two groups were lower than those before operation, but there was no significant difference between the two groups, indicating that the two PCI approaches can improve cardiac function in elderly patients with coronary heart disease.

In conclusion, transradial and femoral PCI have the same effect in the treatment of CHD. However, transradial PCI has faster recovery, lower incidence of postoperative complications and serious cardiovascular adverse events, and higher safety, which can be used as the preferred treatment for CHD patients.

\section{Acknowledgements:}

This work was supported by Zhuhai People's Hospital (Zhuhai Hospital Affiliated with Jinan University), The First Affiliated Hospital, Sun Yat-sen University and Guangdong Provincial People's Hospital, Li-Le Shi and Wei-Xiang Peng are contributed equally to this work.

\section{Conflict of interest:}

The authors report no conflicts of interest.

\section{REFERENCES}

1. Walsh-Sukys MC, Tyson JE, Wright LL, Bauer CR, Korones $\mathrm{SB}$, Stevenson DK, et al. Persistent pulmonary hypertension of the newborn in the era before nitric oxide: practice variation and outcomes. Pediatrics 2000;105(1):14-20.

2. Inhaled nitric oxide in term and near-term infants: neurodevelopmental follow-up of the neonatal inhaled nitric oxide study group (NINOS). J Pediatr 2000;136(5):611-7.

3. Clark RH, Huckaby JL, Kueser TJ, Walker MW, Southgate WM, Perez JA, et al. Low-dose nitric oxide therapy for persistent pulmonary hypertension: 1-year follow-up. J Perinatol 2003;23(4):300-3.

4. Konduri GG, Vohr B, Robertson C, Sokol GM, Solimano A, Singer J, et al. Early inhaled nitric oxide therapy for term and near-term newborn infants with hypoxic respiratory failure: neurodevelopmental follow-up. J Pediatr 2007;150(3):235-40.

5. Kumar VH, Hutchison AA, Lakshminrusimha S, Morin FC, Wynn RJ, Ryan RM. Characteristics of pulmonary hypertension in preterm neonates. J Perinatol 2007;27(4):214-9.

6. Hamvas A, Cole FS, Nogee LM. Genetic disorders of surfactant proteins. Neonatology 2007;91(4):311-7.

7. Hernández-Díaz S, Van Marter LJ, Werler MM, Louik C, Mitchell AA. Risk factors for persistent pulmonary hypertension of the newborn. Pediatrics 2007;120(2):e272-82.

8. Fornaro E, Li D, Pan J, Belik J. Prenatal exposure to fluoxetine induces fetal pulmonary hypertension in the rat. Am J Respir Crit Care Med 2007;176(10):1035-40.

9. Stankiewicz P, Sen P, Bhatt SS, Storer M, Xia Z, Bejjani BA, et al. Genomic and genic deletions of the FOX gene cluster on 16q24. 1 and inactivating mutations of FOXF1 cause alveolar capillary dysplasia and other malformations. Am J Hum Genet 2009;84(6):780-91.

10. Weijerman ME, van Furth AM, van der Mooren MD, Van Weissenbruch MM, Rammeloo L, Broers CJ, et al. Prevalence of congenital heart defects and persistent pulmonary hypertension of the neonate with Down syndrome. Eur J Pediatr 2010;169(10):1195-9.

11. Bishop NB, Stankiewicz P, Steinhorn RH. Alveolar capillary dysplasia. Am J Respir Critic Care Med 2011;184(2):172-9.

12. Byers HM, Dagle JM, Klein JM, Ryckman KK, McDonald EL, Murray JC, et al. Variations in CRHR1 are associated with persistent pulmonary hypertension of the newborn. Pediatr Res 2012;71(2):162-7.

13. Aikio O, Metsola J, Vuolteenaho R, Perhomaa M, Hallman $\mathrm{M}$. Transient defect in nitric oxide generation after rupture of fetal membranes and responsiveness to inhaled nitric oxide in very preterm infants with hypoxic respiratory failure. J Pediatr 2012;161(3):397-403.

14. Van Marter LJ, Hernandez-Diaz S, Werler MM, Louik C, Mitchell AA. Nonsteroidal antiinflammatory drugs in late pregnancy and persistent pulmonary hypertension of the newborn. Pediatrics 2013;131(1):79-87.

15. Check J, Gotteiner N, Liu X, Su E, Porta N, Steinhorn R, et al. Fetal growth restriction and pulmonary hypertension in premature infants with bronchopulmonary dysplasia. J Perinatol 2013;33(7):553-7. 
16. Mourani PM, Abman SH. Pulmonary vascular disease in bronchopulmonary dysplasia: pulmonary hypertension and beyond. Curr Opin Pediatr 2013;25(3):329-37.

17. Bendapudi P, Rao GG, Greenough A. Diagnosis and management of persistent pulmonary hypertension of the newborn. Paediatr Respir Rev 2015;16(3):157-61.

18. Huybrechts KF, Bateman BT, Palmsten K, Desai RJ, Patorno E, Gopalakrishnan C, et al. Antidepressant use late in pregnancy and risk of persistent pulmonary hypertension of the newborn. JAMA 2015;313(21):2142-51.

19. Hooper CW, Delaney C, Streeter T, Yarboro MT, Poole S, Brown N, et al. Selective serotonin reuptake inhibitor exposure constricts the mouse ductus arteriosus in utero. Am J Physiol Heart Circ Physiol 2016;311(3):H572-81.
20. Mei M, Cheng G, Sun B, Yang L, Wang H, Sun J, et al. EDN1 gene variant is associated with neonatal persistent pulmonary hypertension. Sci Rep 2016;6(1):1-7.

21. Nörby U, Forsberg L, Wide K, Sjörs G, Winbladh B, Källén K. Neonatal morbidity after maternal use of antidepressant drugs during pregnancy. Pediatrics 2016;138(5).

This is an open access article distributed under the terms of the Creative Commons Attribution-NonCommercial-ShareAlike 3.0 License, which allows others to remix, tweak, and build upon the work non-commercially, as long as the author is credited and the new creations are licensed under the identical terms

This article was originally published in a special issue, "Diagnostic and Therapeutic Advances in Biomedical Research and Pharmaceutical Sciences"

Indian J Pharm Sci 2021:83(5) spl issue "128-132" 